\title{
Role of medical surveillance in detecting baker's asthma in Taif city, Saudi Arabia
}

\author{
Abdullah Alquraishi*, Nesriene El Margoushy \\ Medical Collage, Taif University, Saudi Arabia
}

\begin{abstract}
Objective: The aim of this cross-sectional study was to assess the role of work related symptoms and medical surveillance in detecting occupational baker's asthma, assess incidence of baker's asthma in Taif city in Saudi Arabia, and detect the underlying causes such as hazards or exposures to any harmful materials.

Methods: This was a cross-sectional study conducted in the duration between November 2016 and May 2017. This study included all bakery workers in Taif city in Saudi Arabia. The collected data included subjects' age, diagnosis with baker's asthma, exposure to flour dust, smoking status, eye symptoms, and respiratory tract symptoms. The study was limited by the small sample size.

Results: A total of 47 subjects were recruited in this study. The mean \pm SD age was $37.4 \pm 8.7$ years. The median (IQR) years of exposure to flour dust was 6 (9) years. The majority of subjects ( $n=40,85.1 \%)$ were non-smokers. only 2 subjects $(4.3 \%)$ reported experiencing eye symptoms, while 4 subjects $(8.5 \%)$ reported experiencing upper respiratory tract symptoms. In this sample population, none of the subjects were diagnosed with baker's asthma. Upper respiratory tract symptoms were found to be significantly more prevalent $(\mathrm{p}=0.004)$ in subjects with severe exposure of flour dust $(100 \%)$, than subjects with minimal (7.1\%) and moderate exposure (5.6\%). No statistically significant association was found between upper respiratory tract symptoms and each of smoking, eye symptoms, age, and years of exposure to flour dust.
\end{abstract}

Conclusion: Due to sample size limitations, we encourage conducting further studies to investigate baker's asthma in Saudi Arabia.

\section{Introduction}

Asthma is defined as a heterogeneous disease that is usually distinguished by chronic inflammation of the airway. It is characterized by history of wheeze, shortness of breath (SOB), chest tightness and cough, along with expiratory airflow limitation [1].

Occupational asthma (OA) is occurring due to inhalation of hazardous substances in workplace. It is often under-diagnosed and under-reported, as Symptoms may appear after months or years, even decades $[2,3,4]$. Baker's asthma is one of the most common sorts of occupational asthma that bakery employees develop after exposure to multiple allergens, including but not limited to, baking flour, wheat, rye, or yeast $[5,6]$. Researchers found that bakers mostly suffer from allergic rhinitis, allergic conjunctivitis and most bakers show symptoms of wheat flour sensitivity [7]. Many studies have demonstrated that baker's asthma can be life threatening and eventually affect the ability to work [8].

Maximal exposure limits (MEL) should be in the range of 0.5-1.0 $\mathrm{mg} / \mathrm{m}^{3}$ in order to prevent a substantial fraction of asthma, rhinitis, and sensitization to flour [3]. When bakers, who are sensitive to flour dust, are exposed to elevated levels of dust over a long period of time, eye and/ or nose symptoms are first manifested before asthma [9]. Many studies highlighted that the frequency of the sensitization to flour dust increases with the level of exposure; this means that either long duration, or high levels of exposure to flour dust can result in a greater risk of developing allergy and asthma [9,10]. Symptoms usually resolve when exposure to the causative allergens is stopped, with continued exposure this can lead to developing baker's asthma in sensitive employees [8].
Spirometry, histamine and allergen-specific inhalation challenge tests are performed to diagnose occupational respiratory disease $[11,12]$. The key management of any occupational asthma is making the diagnosis and removing the subject from exposure as quickly as possible after the onset of symptoms. Asthma may improve if the management was done both rapidly and efficiently $[13,14]$.

As reviewed by $\mathrm{C}$ Lemière, a combination of avoiding further exposure to sensitizing agents, reduction in exposure to irritant agents and pharmacotherapy based on the severity of asthma is the corner stone of occupational asthma management [15].

Prevention of baker's asthma is done through medical surveillance program to keep workers healthy and ensure that employers are meeting the Occupational Safety and Health Administration (OSHA) in an agency. Medical surveillance aimed to detect potential hazards in workplace before irreversible health issues occur [16]. Data about occupational asthma, including baker's asthma, in Saudi Arabia is still lacking, hence we aimed to conduct this cross-sectional study to serve as a pilot study for further investigations.

Our results may help highlighting the significance, and the burden of occupational asthma and investigating the role of medical surveillance in detecting baker's asthma in Saudi Arabia.

${ }^{*}$ Correspondence to: Nesriene El Margoushy, Medical Collage, Taif University, Saudi Arabia, E-Mail: alshareef.orl@gmail.com

Received: July 16, 2019; Accepted: August 23, 2019; Published: August 30, 2019 


\section{Materials and methods}

\section{Study design}

This was a cross-sectional study that was conducted in Taif city in Saudi Arabia. The aim of this study was to assess the role of workrelated symptoms and medical surveillance in detecting occupational baker's asthma, assess incidence of baker's asthma in Taif city in Saudi Arabia, and detect the underlying causes such as hazards or exposures to any harmful materials.

\section{Data collection}

During the period between November 2016 and May 2017, a total of 47 subjects were recruited from bakery shops in Taif city in Saudi Arabia. A questionnaire was utilized to collect subjects' data. The collected data included subjects' age, diagnosis with baker's asthma, exposure to flour dust, smoking status, eye symptoms, and respiratory tract symptoms.

\section{Statistical methodology}

Data were represented in terms of frequencies (number of subjects) and valid percentages for categorical variables. Mean \& standard deviations (SD) were used to describe normally distributed numerical variables, and median \& inter quartile range (IQR) were used to describe non-normally distributed numerical variables. Chi2 test was used to compare categorical variables between the subgroups, and MannWhitney test was used to compare numerical variables between the subgroups. All $\mathrm{P}$ values $<0.05$ were considered statistically significant. IBM SPSS (Statistical Package for the Social Science; IBM Corp, Armonk, NY, USA) was used to perform all statistical calculations, version 16 for Microsoft Windows.

\section{Ethical considerations}

Institutional research ethics board approval was acquired prior to initiating any study-related procedures.

\section{Results}

\section{Subject's Age}

We found that the mean \pm SD age for the 47 recruited subjects was $37.4 \pm 8.7$ years, with a minimum of 24 years and a maximum of 64 years.

\section{Diagnosis}

It was found that none of the subjects were diagnosed with baker's asthma in our sample population.

\section{Exposure to flour dust}

Our data showed that the median (IQR) years of exposure to flour dust was 6 (9) years, with a minimum of 1 year and a maximum of 30 years. In regards to level of exposure, data showed that 28 (59.6\%) subjects reported minimal exposure to flour dust, 18 (38.3\%) reported moderate exposure, and only 1 (2.1\%) reported severe exposure.

\section{Smoking}

It was found that the majority of subjects ( $n=40,85.1 \%$ ) were nonsmokers while 7 subjects (14.9\%) were smokers.

\section{Eye symptoms}

We found that 45 subjects $(95.7 \%)$ reported that they did not experience eye symptoms, while only 2 subjects (4.3\%) reported experiencing these symptoms. One subject (2.1\%) reported red eye and itching, and the other one (2.1\%) reported red eye in the first 2 weeks.

\section{Upper \& Lower respiratory tract symptoms}

In regards to upper respiratory tract symptoms, 43 subjects (91.5\%) reported that they did not experience upper respiratory tract symptoms, while only 4 subjects (8.5\%) reported experiencing these symptoms.

Two subjects (4.3\%) experienced cough and sneezing, 1 (2.1\%) experienced cold and sneezing, and 1 subject $(2.1 \%)$ experienced sneezing only. On the other hand, no subjects reported experiencing any lower respiratory tract symptoms.

\section{Exposure of flour dust \& respiratory tract symptom}

Upper respiratory tract symptoms were found to be significantly more prevalent $(\mathrm{p}=0.004)$ in subjects with severe exposure of flour dust (100\%), rather than subjects with minimal (7.1\%) and moderate exposure (5.6\%).

\section{Smoking \& respiratory tract symptoms}

Data showed that $14.3 \%$ of subjects who smoked had upper respiratory tract symptoms, while a lower percentage of non-smoker subjects $(7.5 \%)$ had upper respiratory tract symptoms. However, no statistically significant $(\mathrm{p}=0.488)$ association was found between smoking and upper respiratory tract symptoms.

\section{Eye symptoms \& respiratory tract symptoms}

Data showed that $50 \%$ of subjects with eye symptoms had upper respiratory tract symptoms, while a lower percentage of subjects without eye symptoms (6.7\%) had upper respiratory tract symptoms. Also, no statistically significant $(\mathrm{p}=0.165)$ association was found between eye symptoms and upper respiratory tract symptoms.

\section{Age \& respiratory tract symptoms}

Subjects with upper respiratory tract symptoms were found to be older than those without symptoms. Mean \pm SD age was $38.5 \pm 7.3$ years and $37.3 \pm 8.9$ years respectively. However, no statistically significant $(\mathrm{p}=0.796)$ association was found between age and upper respiratory tract symptoms.

\section{Years of exposure to flour dust \& respiratory tract symptoms}

The median (IQR) years of exposure to flour dust in subjects with upper respiratory tract symptoms was found to be $6(8)$ years, while in subjects without upper respiratory tract symptoms, median (IQR) was $10(5)$ years. No statistically significant $(\mathrm{p}=0.566)$ association was found between years of exposure to flour dust and upper respiratory tract symptoms.

\section{Discussion}

Previous studies have reported that occupational asthma constitutes $10-15 \%$ of the total adult asthma cases $[17,18]$. Studies also found that workers who are exposed to flour dust have higher risk of developing occupational respiratory disease [6,19]. Previous studies have also discussed the considerable burden of the disease in this population [20,21]. However, in Saudi population, data about occupational asthma is still lacking, and needs further investigation. In 2016, MS Al-Moamary reviewed guidelines for the diagnosis and management of asthma in adults and children developed by the Saudi Initiative for Asthma (SINA) group. It was stated that many triggers such as allergens, viral infections, pollutants, drugs, and occupational agents 
can lead to acute asthma exacerbations [22]. In 2015, the prevalence of asthma in Saudi Arabia was reported to be $4.05 \%$ [23]. However, there was data about occupational asthma, particularly baker's asthma, in Saudi Arabia.

In the current study, none of the subjects were diagnosed with baker's asthma in our sample population. In 2006, another study conducted investigated baker's asthma in 59 flour mill workers in Jalagaon city. This study categorized the ventilatory impairment of flour mill workers on the basis of air flow obstruction, restrictive defect, and expiratory flow rate. It was reported that $32 \%, 45 \%$, and $23 \%$ had normal expiratory flow rate, moderate expiratory flow rate with possible respiratory defects, and severe respiratory defects, respectively [24].

Our current results showed that $8.5 \%$ and $4.3 \%$ of subjects experienced upper respiratory tract symptoms and eye symptoms, respectively, while no subjects reported any lower respiratory tract symptoms. Each of red eye and itching, and red eye in the first 2 weeks was reported by $2.1 \%$ of subjects. Cough and sneezing were reported in $4.3 \%$, cold and sneezing in $2.1 \%$, and sneezing only in $2.1 \%$. This was found to be compatible, however lower, with results from another studies that reported respiratory tract symptoms prevalence between $5 \%$ and $21 \%$ in bakery workers [25]. In another cross-sectional study, nasal/ eye symptoms prevalence was found to be $46.4 \%$ of the total reporting symptoms and $26.8 \%$ of the work-related reporting symptoms [26].

In accordance with literature, upper respiratory tract symptoms were found to be significantly more prevalent in subjects with severe exposure of flour dust $[6,10]$. Our study reported that each of smoking, eye symptoms, age, and years of exposure to flour dust had no statistically significant association with developing upper respiratory tract symptoms.

On the other hand, another study that was conducted in Egypt, showed that a significantly $(\mathrm{p}<0.002)$ higher prevalence of respiratory symptoms $(96.2 \%)$ was found in workers with a longer duration of employment/ exposure than those with shorter duration (83.3\%).

Furthermore, the same study reported a highly statistically significant association between the presence of respiratory symptoms and tobacco smoking. Also, older age was found to have a significant association with the presence of respiratory symptoms, as $93 \%$ of workers $<40$ developed respiratory symptoms while $83.3 \%$ of workers $>40$ years did not develop the disease [9].

\section{Conclusion}

Our study showed the presence of respiratory symptoms is significantly associated with severe exposure of flour dust, while in terms of smoking, eye symptoms, age, and years of exposure to flour dust, there was no statistically significant association with developing respiratory tract symptoms.

Due to sample size limitations, we encourage conducting further studies to investigate baker's asthma in Saudi Arabia. We aim by this to improved dust control measures in the grain industry across the country.

\section{References}

1. Reddel HK, Levy ML (2015) The GINA asthma strategy report: what's new for primary care?. NPJ Prim Care Respir Med 25: 15050. [Crossref]

2. Pepys J (1982) Occupational asthma: an overview. Curr Allergy Asthma Rep 24: 534538. [Crossref]
3. Brisman J (2002) Baker's asthma. Occupat Environment Med 59: 498-502.

4. Lemière C (2013) When to suspect occupational asthma. Can Respir J 20: 442-444.

5. Houba R, Doekes G, Heederik D (1998) Occupational respiratory allergy in bakery workers: a review of the literature. Am J Ind Med 34: 529-546. [Crossref]

6. Stobnicka A, Górny RL (2015) Exposure to flour dust in the occupational environment Int J Occup Saf Ergon 21: 241-249. [Crossref]

7. Quirce S, Diaz-Perales A (2013) Diagnosis and management of grain-induced asthma. Allergy Asthma Immunol Res 5: 348-356. [Crossref]

8. Sander I, Rihs HP, Brüning T (2016) A further wheat allergen for baker's asthma: Tri a 40. J Allerg Clin Immunol 137: 1286.

9. Mohammadien HA, Hussein MT, El-Sokkary RT (2013) Effects of exposure to flour dust on respiratory symptoms and pulmonary function of mill workers. Euro Respir J 62: 745-753.

10. Said AM, AbdelFattah EB, Almawardi AA (2017) Effects on respiratory system due to exposure to wheat flour. Egypt J Chest Dis Tuberculosis 66: 537-548.

11. Walusiak J, Hanke W, Gorski P (2004) Respiratory allergy in apprentice bakers: do occupational allergies follow the allergic march?. Allergy 59: 442-450. [Crossref]

12. Wiszniewska M, Nowakowska-Swirta E, Palczynski C (2011) Diagnosing of bakers' respiratory allergy: is specific inhalation challenge test essential?. Allergy Asthma Proc 32: 111. [Crossref]

13. Lombardo LJ, Balmes JR (2000) Occupational asthma: a review. Environ Health Perspect 108: 697. [Crossref]

14. Fishwick D, Barber CM, Bradshaw LM (2008) Standards of care for occupational asthma. Thorax 63: 240-250.

15. Lemière C, Bernstein DI (2018) Occupational asthma: Management, prognosis, and prevention.

16. Koh D, Aw TC (2003) Surveillance in occupational health. Occupat Environ Med 60 705-710.

17. Blanc PD, Toren K (1999) How much adult asthma can be attributed to occupational factors?. Am J Med 107:580-587. [Crossref]

18. Balmes J, Becklake M, Blanc P (2003) American Thoracic Society Statement Occupational contribution to the burden of airway disease. Am J Respir Crit Care Med 167: 787-797. [Crossref]

19. Baur X, Degens PO, Sander I (1998) Baker's asthma: still among the most frequent occupational respiratory disorders. J Allergy Clin Immunol 102: 984-997.

20. Jacobs J, Meijster T, Meijer E (2008) Wheat allergen exposure and the prevalence of work-related sensitization and allergy. Allergy 63: 1597-1604. [Crossref]

21. Gautrin D, Ghezzo H, Infante-Rivard C (2008) Long-term outcomes in a prospective cohort of apprentices exposed to high-molecular-weight agents. Am J Respir Crit Care Med 177: 871-879. [Crossref]

22. Al-Moamary MS, Alhaider SA, Idrees MM (2016) The Saudi Initiative for Asthma-2016 update: Guidelines for the diagnosis and management of asthma in adults and children. Ann Thorac Med 11: 3. [Crossref]

23. Moradi-Lakeh M, El Bcheraoui C, Daoud F (2015) Prevalence of asthma in Saudi adults: findings from a national household survey, 2013. BMC Pulmon Med 15: 77.

24. Wagh ND, Pachpande BG, Patel VS (2006) The influence of workplace environment on lung function of flour mill workers in Jalgaon urban center. $J$ Occupat Health 48: 396-401. [Crossref]

25. Dust Co (2002) Baker's allergy and asthma-Towards preventive strategies. Curr Allergy Clin Immunol 15: 161.

26. Jeffrey P, Griffin P, Gibson M (1999) Small bakeries-a cross-sectional study of respiratory symptoms, sensitization and dust exposure. Occupat Med 49: 237-241.

Copyright: (C2019 Alquraishi A. This is an open-access article distributed under the terms of the Creative Commons Attribution License, which permits unrestricted use, distribution, and reproduction in any medium, provided the original author and source are credited. 